\title{
Tagalog adaptation of the Multilingual Assessment Instrument for Narratives: History, process and preliminary results
}

\author{
Kathleen Kay Amora \\ University of Groningen, University of Potsdam, University of Eastern Finland
}

\section{Rowena Garcia}

Max Planck Institute for Psycholinguistics

\section{Natalia Gagarina}

Leibniz-Zentrum Allgemeine Sprachwissenschaft (ZAS)

This paper briefly presents the current situation of bilingualism in the Philippines, specifically that of Tagalog-English bilingualism. More importantly, it describes the process of adapting the Multilingual Assessment Instrument for Narratives (LITMUSMAIN) to Tagalog, the basis of Filipino, which is the country's national language. Finally, the results of a pilot study conducted on Tagalog-English bilingual children and adults $(\mathrm{N}=27)$ are presented. The results showed that Story Structure is similar across the two languages and that it develops significantly with age.

\section{Introduction}

This paper expounds the bilingual history of the Philippines as well as the processes involved in adapting the Language Impairment Testing in Multilingual Settings - Multilingual Assessment Instrument for Narratives (LITMUS-MAIN, hereafter MAIN; Gagarina et al., 2012, 2015, 2019) to Tagalog/Filipino. To fill the gap in the narrative literature among understudied language combinations, a pilot study was conducted to investigate narrative macrostructure, particularly Story Structure (Story Grammar Elements) of Tagalog-English bilingual children, who are 5 and 10 years of age, and a control group of Tagalog-English bilingual adults in both languages while telling a picture-based fictional narrative. This study offers a cross-linguistic comparison between Tagalog and English using MAIN across the same set of participants of different age groups. 


\section{$2 \quad$ Language use in the Philippines}

\subsection{History of bilingualism in the Philippines}

Bilingualism has been the part the Philippine history since the 1600s. The Philippines is considered as one of the countries with a high number of distinct languages (ranked 25th out of 232 countries with a score of 0.842) in the recent Greenberg Linguistic Diversity Index with around 183 local languages (Eberhard, Simons, \& Fennig, 2019a). Since the Philippines is a linguistically diverse country, it has two official languages - Filipino and English. This paper focuses on the use of Tagalog (basis of Filipino) and English in bilingual children and adults. Tagalog, a verb initial language with a distinct voice marking system, belongs to the MalayoPolynesian branch of the Austronesian linguistic family and has over 23 million native (L1) and second language (L2) speakers (Eberhard, Simons, \& Fennig, 2019b; Schachter \& Otanes, 1972).

Tagalog native speakers are mostly located in the National Capital Region, also more commonly known as Metro Manila, the southern parts of Luzon and in some parts of Central Luzon (Himmelmann, 2005). Based on the 2000 Philippine census, aside from Tagalog, other Philippine-languages (e.g., Cebuano, Ilocano, Bikolano) are also commonly used in Metro Manila households (Mahboob \& Cruz, 2013; Philippine Statistics Authority, 2003). Foreign languages also influenced the Philippines due to trade and colonization. Spanish and English, as well as Asian languages such as Malay and Chinese, heavily influenced Tagalog's lexicon and phonology and some aspects of morphosyntax (Himmelmann, 2005).

When the United States of America (USA) gained control of the Philippines from Spain, English replaced Spanish as the official language and became the common medium of education, press, and speech during the 1900s. This foreign occupation led to the "Americanization" of the Philippines, where English took a dominant role in public education to further the colonial motives of the colonizers (Mahboob \& Cruz, 2013; Tupas \& Lorente, 2014). The locals also initially embraced learning English as it provided them benefits in civil service, career and politics (Tupas \& Lorente, 2014). This prestige status given to English than any other vernacular languages of the Philippines led to a negative reaction later on. The Philippines eventually clamoured for the establishment of national language to regain political independence and collective identity after years of colonization, as English symbolized repression and supremacy of the colonizers (Tupas \& Lorente, 2014).

As a result, in the 1930s, Tagalog became the basis for the national language which was later renamed as Pilipino for political reasons (Tupas \& Lorente, 2014). However, in 1973, English and Pilipino, which became Filipino in 1987, were both established as the official languages of the Philippines; this has been the case up until the present (Ledesma \& Morris, 2005; Tupas \& Lorente, 2014). The differences between Filipino and Tagalog are purely lexical

in nature, with the Commission of the Filipino Language (KWF) expanding Filipino by adding cognates and loan words from other Philippine languages as well as foreign languages (Himmelmann, 2005; Paz, 1996). 
The usage of English and Filipino in schools paved the way for Bilingual Education Program (BEP) in the entire Philippines which lasted until 2009, wherein Filipino and English are the main media of instruction for social sciences as well as life sciences and mathematics, respectively, since Grade 1 regardless of their native languages (Tupas \& Lorente, 2014). This BEP meant that those who come from non-Tagalog areas learn and use two languages in school, whereas those who hail from Tagalog-speaking regions only need to additionally learn English (Smolicz \& Nical, 1997; Tupas \& Lorente, 2014).

However, after years of BEP implementation, unsatisfactory results, especially in the non-Tagalog areas and the lower ranking of the Philippines in the Sciences and Mathematics tests, brought impending changes to this long-running bilingual curriculum around 2009 to 2013 (Martin, 2015). In 2013, the Department of Education institutionalized the MotherTongue Based Multilingual Education (MTB-MLE) policy, which started in 2009, wherein schools would teach scientific and mathematic concepts using the children's native languages in kindergarten and in the first three years of primary school (Manabat, 2016). Since then, especially in Metro Manila, English and Tagalog are similarly present in everyday contexts, may it be speech or print. English dominates schools, mass and print media whereas Tagalog is frequently present at home and in entertainment such as in radio and on television (Ledesma \& Morris, 2005). In their study of 81 Tagalog-English bilingual kindergarten boys in Metro Manila, Ledesma and Morris (2005) found that as the boys reached the start of the first grade, both languages were used equally in social contexts, but English dominated in media and formal contexts (i.e., school setting).

\subsection{The current status of Tagalog-English bilingualism}

Despite the constant usage of both Tagalog and English in everyday situations and curriculum changes, a dominant use of English at home is becoming prevalent as many parents talk more to their children in English than Tagalog nowadays (Quebral, 2018). According to Quebral (2018), English proficiency has been a status symbol for years as those who speak it fluently are regarded as smarter and more affluent. Moreover, Filipinos deem English to be the language with high prestige, which functions as a measure of social stratification, where fluent speakers of English are regarded as belonging to the highly educated middle to upper societal class (Ledesma \& Morris, 2005; Sicam \& Lucas, 2016; Tupas, 2003; Vizconde, 2006). This mindset continues to exist today, thus some parents talk to their children exclusively in English (Quebral, 2018) and these children only learn Tagalog at a later age.

Private schools also prefer to use English as the medium of instruction from the first grade to college where students are trained to speak English in all settings, except during Filipino classes (Ledesma \& Morris, 2005; Smolicz, 1984). Lastly, English also plays a privileged role in social and economic advancements, global competitiveness of Filipinos in the labor market as well as perceived as the most preferred language in higher educational contexts (Lorente, 2013; Mahboob \& Cruz, 2013; Pascasio, 2005). Nevertheless, the usage of both Tagalog and English is widespread in the capital, Manila, and its nearby cities and regions. Tagalog is often used during personal and social conversations whereas English is frequently 
used in government publications, law, business and commerce (Ledesma \& Morris, 2005; Vizconde, 2006).

This everyday exposure to both languages in Manila and nearby regions results in regular code-switching. Code-switching occurs when bilingual speakers alternate between languages during discourse to fill linguistic gaps and to compensate for word finding issues (Moreno, Federmeier, \& Kutas, 2002). Similar to code switching in Hispanic speakers between Spanish and English that resulted in appearance of Spanglish, this mixed Tagalog-English speech is called Taglish. Taglish is usually used by middle-class and educated Filipinos in informal settings to convey a message more efficiently and concisely (Bautista, 2004). This type of code-switching is common in print (i.e., on signs) and especially in speech for both children and adults and has fascinated researchers around the world (Thompson, 2003; Wei, 2000). These switches give a glimpse on how Tagalog and English interact together in different contexts. As there are no standardized instruments that could capture this phenomenon, narrative production could be used to observe this.

\section{$3 \quad$ MAIN and its adaptation to Tagalog}

Gagarina et al. (2012) originally designed Multilingual Assessment Instrument for Narratives (MAIN) to assess narrative comprehension and production abilities of children from 3 to 10 years of age. However, recent work has showed that MAIN stories can also be used with adults (Gagarina, Bohnacker \& Lindgren, 2019). One of the aims of MAIN is to be able to carry out comparable examination of narrative skills in both languages of bilingual individuals. Additionally, MAIN can be used as a screening tool to classify children at risk for Developmental Language Disorders (DLD). MAIN is part of the Language Impairment Testing in Multilingual Settings (LITMUS) test battery, which was funded by the COST Action IS0804 Language Impairment in a Multilingual Society: Linguistic Patterns and the Road to Assessment (2009-2013) (see Armon-Lotem, de Jong, \& Meir, 2015).

MAIN is composed of four parallel stories. Each story consists of six pictures that are culturally robust and controlled for linguistic complexity and narrative structure (Gagarina et al., 2012). This makes the stories comparable when done in different languages. Moreover, MAIN contains a detailed description for investigating macrostructure using a multidimensional model with comparable categories to Stein and Glenn (1979)'s story grammar framework to determine Story Structure, but prioritizing the Goals and including Internal State as an Initiating Event (Gagarina et al., 2012, 2019). The instrument can be used to elicit narratives in three modes: model story, retelling and telling (Gagarina et al., 2012). MAIN contains protocols for analyzing macrostructure in three parts: Story Structure, Story Complexity and added Internal State Terms (ISTs) to further express parts of macrostructure. 


\subsection{Translation and Adaptation of MAIN to Tagalog}

Similar to the problems found with other understudied languages, the Philippines has very limited linguistic tools in different languages and dialects. Moreover, there are no standardized instruments in Tagalog that would assess and investigate children's specific linguistic skills. Most teachers, researchers, and clinicians use Western assessment tools on children and just directly translate them on the fly, with less consideration of the different linguistic properties of Tagalog. However, the results for the standardized tests in English-speaking countries cannot be directly applied to Tagalog due to several obvious cultural and language-specific differences. Instead, clinicians and researchers frequently use criterion-based and dynamic assessments to obtain linguistic data for children. Hence, there is a high need for assessment tools in Tagalog. Given that validated, normed and standardized linguistic tests need years to develop, providing a narrative assessment tool in Tagalog could help clinicians, teachers, and linguists gain a better understanding of children's linguistic capabilities. For this reason, the first author (a native speaker) first translated and then performed the full adaptation of MAIN to Tagalog with the help of the second author (also a native speaker), and another Tagalog-native linguist, Ivan Paul Bondoc. This is the first MAIN adaptation to an Austronesian language. The two Tagalognative linguists carefully reviewed the entire Tagalog translation of the manual, especially the story scripts, to ensure naturalness, appropriateness, and consistency. After two rounds of evaluation, discussions, backwards translation and revision, the final Tagalog story scripts for Maliit na Ibon 'Baby Birds', Maliit na Kambing 'Baby Goats', Pusa 'Cat' and Aso 'Dog' as well as the translation of the manual were finalized.

\subsection{Proposed changes for the adaptation}

Although the authors followed the MAIN adaptation guidelines (Bohnacker \& Gagarina, 2019), evident changes in the Tagalog version as compared to the English one were done. Based on the results of the pilot study (see Section 4), changes in some terminologies were suggested to make the stories more culturally appropriate. Overall, the word counts for Tagalog scripts slightly differed from the English version due to differences in vocabulary and morphological structures. For example, in Tagalog, verbs are only marked for aspect and not tense and always consist of only one word (whereas in English progressive is formed with the use of an auxiliary, e.g., 'is going'). Moreover, in Tagalog, there is no direct one-word translation for a 'boy'. The closest translation is the gender-neutral bata 'child'. Adding the gender and connecting the words together with a linker (e.g., batang lalaki for 'boy') gives the same meaning as its English counterpart. In this case, two words are needed in Tagalog. Another example is the direct translation for 'baby' in Filipino/Tagalog sanggol, a word which does not accurately reflect the

main characters in the Baby Birds and Baby Goats stories (i.e. baby birds and goats, respectively). A more apt translation would be bata 'child'; however, results from the pilot study (see Section 4) showed that children also use maliit 'small' to describe the younger animal. Thus, the latter was used in the story scripts. 
After discussions, some minor revisions to the illustrations and in the physical attributes of the characters were also proposed to make them applicable to the Asian culture, particularly in the Southeast Asian regions. The first author suggested to change the appearance of the boys in the Cat and Dog stories to make them appear more Asian-looking (a typical Filipino child is described as brown-skinned with a black-colored hair). Moreover, even though foxes are familiar to children due to exposure to Western books, the English word 'fox' is more commonly used than the Tagalog word soro 'fox', as evidenced by the responses of the participants, especially the children, in the pilot study. Therefore, the first author suggested to change the fox to a wolf to avoid lexical switches. Even though there are no wolf species in the Philippines, its Tagalog translation 'lobo' is more commonly known to children than the fox's due to its increased prevalence in translated versions of Western stories and in Philippine media. A decision was made to adapt the MAIN pictorial stimuli slightly based on these suggestions. After intensive discussions via e-mail with Natalia Gagarina, the first author of MAIN, and Celestino Oriikiriza, a researcher from Uganda who has encountered similar challenges with the fox picture when testing children in the Luganda language (also known as Ganda), it was decided to change the following aspects:

1) Changes to the physical features of the characters in Cat and Dog, as shown in Figure 1.

2) Changes to the animals in Baby Goats: changing the fox to a wolf and additional fur color changes, leading to two versions of the wolf, one desert wolf that is browner in color, and the 'typical' grey wolf, as shown in Figure 2.

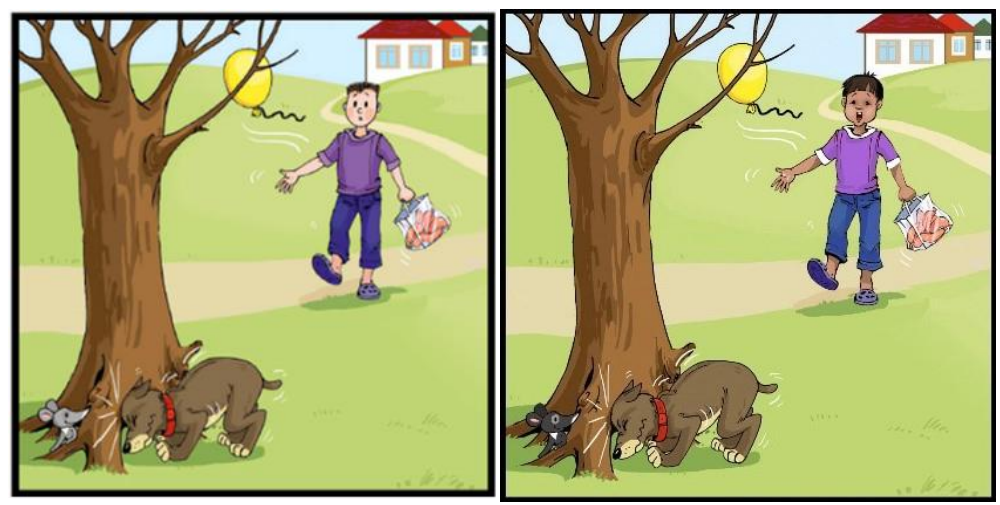

Figure 1. Picture 3, Dog, of the original MAIN stimuli (left), and the proposed changes after considering cultural differences (right). Copyright 2020 by ZAS Papers in Linguistics. 


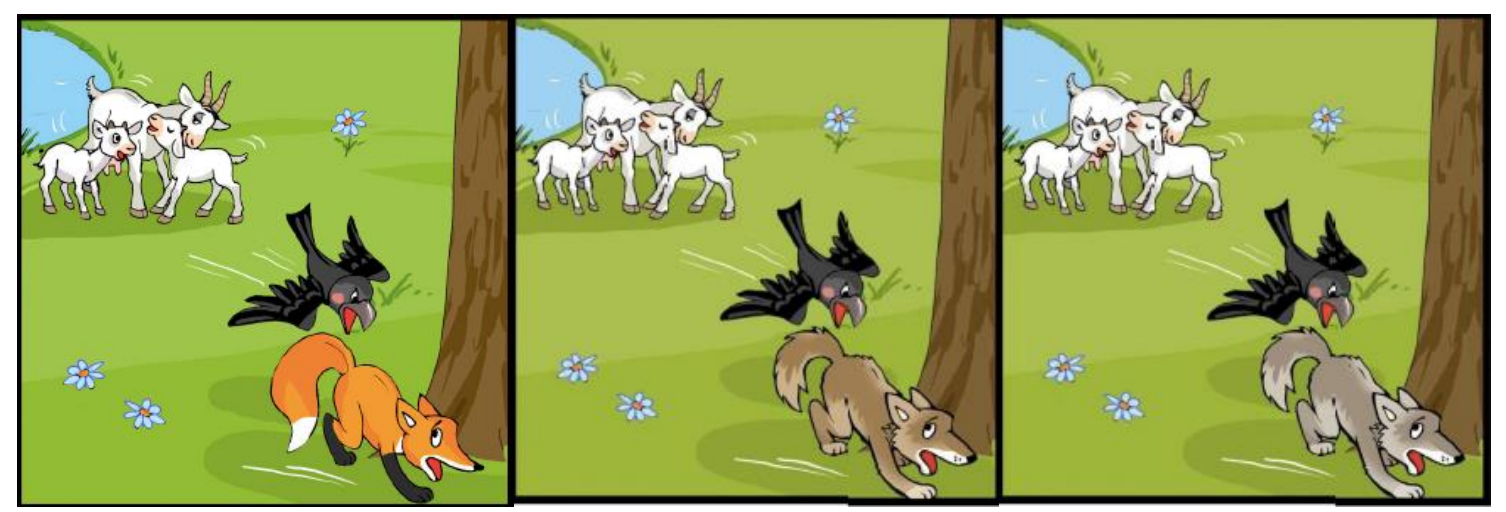

Figure 2. Picture 6, Baby Goats of the original MAIN stimuli (left), the proposes changes after considering cultural differences, desert wolf (middle) and grey wolf (right). Copyright 2020 by ZAS Papers in Linguistics.

\section{$4 \quad$ Pilot study}

After finalizing the translated Tagalog story scripts, the first author conducted a pilot study using only the telling mode with the stories Baby Birds and Baby Goats with 27 typically developing Tagalog-English bilingual participants (six 5-year-old children, 12 10-year-old children and 9 adults). The first author translated the instructions and comprehension questions into Tagalog and also followed the same protocol stated in the English version throughout the entire study.

\subsection{Participants}

The 5-year-old children (mean age: 5;5, age range: 5;4-5;10, SD: 0.2) attended preschool classes at a school in the Metro Manila area. As there were no available screening tests to check the Tagalog and English proficiencies of young children, the participants were recruited based on teacher recommendations. All the participants were reported to be Tagalog-English bilinguals, with Tagalog as their dominant language. The older children (mean age: 10;7, age range: 10;4-11;0, SD: 0.2) were Grade 4 students at a grade school around Metro Manila. The older children answered a basic online screening tool for English proficiency ${ }^{1}$ and the average score was 19.42 out of 20. Prior to the testing, all children were assessed with a non-verbal IQ test called the Raven's Colored Progressive Matrices (Raven, Court, \& Raven, 1976). The adult participants (mean age: 24;0, age range: 22;1-25;6, SD: 1.2) were graduates of a university in Manila and were working as rehabilitation professionals (e.g., physical, occupational, and speech therapists) all over the Metro Manila area. The adults, having completed their academic degrees in English, provided a self-assessment rating of their English proficiency. All rated themselves within above-average to advanced levels (e.g., CEFR self-rating level B2-C1).

All groups were homogenous in terms of social-economic status (middle-class), handedness (all right-handed) and native language (Tagalog). Participants with persisting developmental and neurological problems were excluded from the study. All participants were

\footnotetext{
${ }^{1}$ See https://tv-english.club/education-en/tests-en/placement-tests-en/placement-test-kids-10-16-years-age/
} 
currently exposed mostly to the Tagalog and English languages for communication at home and academic instruction or work, respectively, based on their answers in the MAIN language questionnaire.

In addition to the approval of the University of Groningen's Research Ethics Review Committee (CETO), the parents signed a written consent for their children to participate in the study. Furthermore, the 10-year-old children gave their verbal and written consent prior to the testing. The adult participants personally signed the consent forms, signifying their intent to participate voluntarily. All groups agreed for their sessions to be audio-video recorded. Aside from this, the parents of the children and the adults filled in a revised and Tagalog-translated version of the questionnaire from the MAIN, providing personal information, developmental, educational and speech-language histories, as well as exhaustive information about language exposure and frequency of use. Lastly, most of the participants had started to acquire their L2 before the age of 5, except for one who learned it at 6 years of age (one 10-year-old child).

\subsection{Design and procedure}

The study combined a within-subject design, comparing the bilinguals' two languages, and a between-subjects design, comparing both bilingual narratives across three age groups (i.e., younger children, older children and adults). For narrative production, two picture stories, Baby Birds and Baby Goats were randomly distributed for each language in the telling mode. The order of stories and languages varied per participant and was counterbalanced (e.g., Participant 1 received Baby Birds first, whereas Participant 2 received Baby Goats first). Following the standardized testing procedure, three envelopes containing the same set of pictures were placed in front of the participant. This setup was in adherence to the MAIN protocol to give an illusion of randomness of the stories the participants could get. The envelopes contained picture stimuli which could be opened in a fold-out manner. The participants were asked to tell one of the two stories (i.e., Baby Birds or Baby Goats) in either their L1 or L2, depending on the randomization procedure.

The interval between tasks was around four to seven days to avoid learning and carryover effects. The first author used the same procedure again after the interval, but the language of instruction differed from the first session and the story which was not used in the first session was utilized in the second day of narrative testing. Scripts during elicitation followed the instructions of the MAIN manual wherein only neutral feedback and comments (e.g., okay, well) were used.

\subsection{Results and discussion}

The mean and standard deviations for the Story Structure scores of all groups per language are presented in Figure 3. To check the effect of language in the production of Story Structure elements (maximum score $=17$ points) within groups, a Kruskal-Wallis test was performed. The test showed no differences between languages across all groups. Based on these results, Language did not have any effect on Story Structure scores. These relatively similar Story 
Structure mean scores in both languages across all the groups, younger children (Tagalog: 6.33, English: 6.17), older children (Tagalog: 9.42, English: 9.33) and adults (Tagalog: 10.33, English: 10) support the claim of language invariance.

Furthermore, a separate Kruskal-Wallis test for each language to check for Age effects was considered. Results revealed significant main effects of Age for both Tagalog $\left(\chi^{2}=10.67\right.$, $\mathrm{p}=.005)$ and English $\left(\chi^{2}=8.586, \mathrm{p}=.014\right)$. A post-hoc test using the Wilcoxon rank-sum test with Sidak correction $(\mathrm{p}=.02)$ (see Table 1$)$ to check the differences between groups was also conducted. In Tagalog, there was only one significant difference, i.e., between 5-year-old children and adults ( $\mathrm{W}=52, \mathrm{p}=.004)$, such that adults performed better than the younger children. In English, five-year-old children scored significantly lower than both 10-year-old children $(\mathrm{W}=8.5, \mathrm{p}=.01)$ and adults $(\mathrm{W}=52, \mathrm{p}=.004)$.

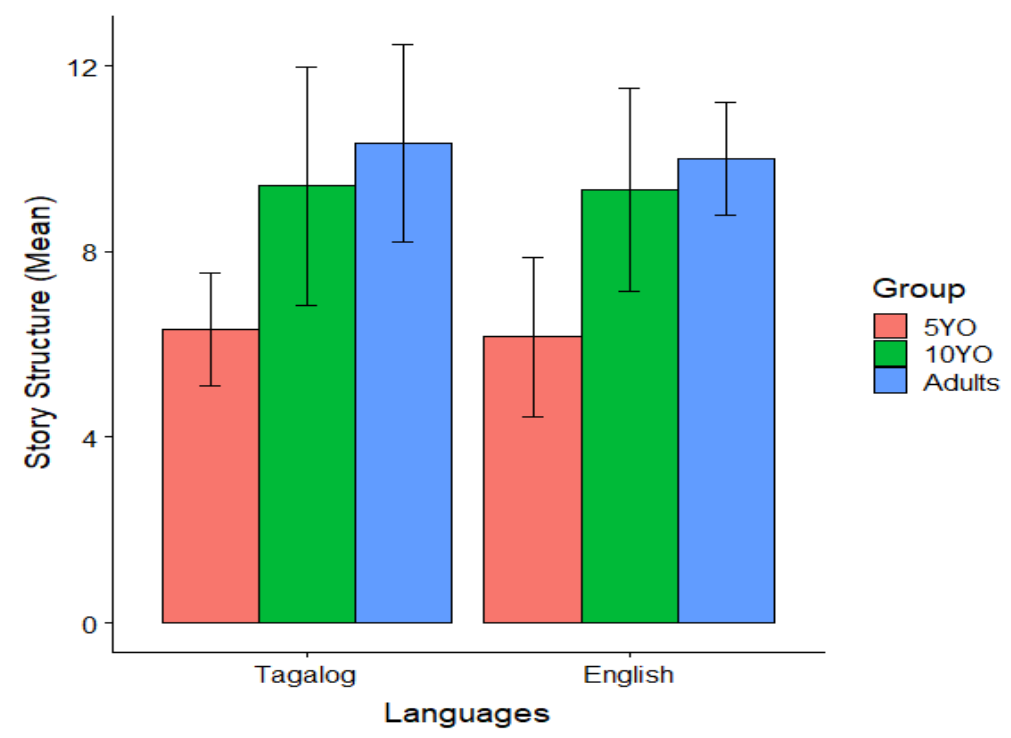

Figure 3. Mean Story Structure scores by language for the three groups. (Error bars show $\pm 1 \mathrm{SD}$.)

Overall, the results showed that Story Structure did not differ across languages. There was no evidence to conclude that narrative macrostructure is language-dependent, supporting the findings from previous studies (Bohnacker, 2016; Fiestas \& Peña, 2004; Gagarina, 2016; Kunnari et al., 2016; Pearson, 2002). The results suggest that narrative structure could indeed be language-invariant in bilinguals, supporting the claim of Otwinowska and co-authors (2018) and Squires and colleagues (2014) about the sharing of conceptual bases of narrative macrostructure for both languages, thus facilitating cross-linguistic transfer. Additionally, this result was interpreted as a possible support for the claim that narrative macrostructure more closely hinged on the cognitive maturation of an individual than on the language (Bohnacker, 2016; Pearson, 2002).

Moreover, the results of the statistical tests showed that the Story Structure increased from 5 years to adulthood in both languages. These results are consistent with previous findings that younger children produced significantly fewer story structure components than older groups (Bohnacker, 2016; Fiestas \& Peña, 2004; Gagarina, 2016; Kunnari et al.,2016; Schneider, Hayward, \& Dubé, 2006; Trabasso \& Nickels, 1992). The results also support the 
previous literature that at age 5, Goal-Attempt-Outcome sequences start to emerge; verifying that the age range of 3-7 years old is crucial for narrative development (Bohnacker, 2016; Trabasso \& Nickels, 1992; Westby, 2014). Moreover, ten-year-olds' narrative structure was indistinguishable from that of adults indicating that the narratives of 10-year-old children are nearly adult-like, similar to the findings of Berman and Slobin (1994) and Trabasso and Nickels (1992). However, even though the results revealed a similar narrative structure, adult narratives are still superior in terms of thematic organization and generalization due to advanced rhetorical thinking, as Berman and Slobin (1994) suggested.

\section{Conclusion}

This study describes the bilingualism status of the Philippines, where Tagalog (or Filipino for which Tagalog is used as basis) and English are the official languages of the country. The Philippines lacks tests in assessing narratives, hence Multilingual Assessment Instrument for Narratives (MAIN) was adapted to Tagalog/Filipino and tested in 27 bilingual TagalogEnglish-speaking children and adults. Results showed that Story Structure increased with age but did not differ between Tagalog and English in any of the investigated age groups, suggesting universality across languages.

\section{Disclosures}

The content of this chapter is based on the first author's unpublished Master's thesis entitled: Narrative Structure and Complexity of typically developing Tagalog-English bilingual children and adults (2019) supervised by R. Garcia of Max Planck Institute for Psycholinguistics, N. Gagarina of Leibniz-Zentrum für Allgemeine Sprachwissenschaft (ZAS), and I. Sekerina of City University of New York.

\section{$7 \quad$ References}

Armon-Lotem, S., de Jong, J., \& Meir, N. (Eds.). (2015). Assessing multilingual children: Disentangling bilingualism from language impairment. Bristol: Multilingual matters.

Bautista, M. L. S. (2004). Tagalog-English Code Switching as a Mode of Discourse. Asia Pacific Education Review, 5(2), 226-233.

Berman, R.A., \& Slobin, D. I. (1994). Relating events in narrative: A crosslinguistic developmental study. Hillsdale, NJ: Erlbaum.

Bohnacker, U. (2016). Tell me a story in English or Swedish: Narrative production and comprehension in bilingual preschoolers and first graders. Applied Psycholinguistics, 37(1), 19-48. 
Bohnacker, U. \& Gagarina, N. (2019). Background on MAIN - Revised, how to use it and adapt it to other languages. ZAS Papers in Linguistics, 63, iv-xii.

Eberhard, D. M., Simons, G. F., \& Fennig, C. D. (2019a). Summary by country. Retrieved 2 June 2019, from https://www.ethnologue.com/statistics/country.

Eberhard, D. M., Simons, G. F., \& Fennig, C. D. (2019b). Tagalog. Retrieved 15 July 2019, from https://www.ethnologue.com/language/tgl.

Fiestas, C. E., \& Peña, E. D. (2004). Narrative discourse in bilingual children: Language and task effects. Language, Speech, and Hearing Services in Schools, 35(2), 155-168.

Gagarina, N. (2016). Narratives of Russian - German preschool and primary school bilinguals: Rasskaz and Erzaehlung. Applied Psycholinguistics, 37(1), 91-122.

Gagarina, N., Bohnacker, U., Lindgren, J. (2019). Macrostructureal organisation of adults' oral narrative texts. ZAS Papers in Linguistics, 62, 190-208.

Gagarina, N., Klop, D., Kunnari, S., Tantele, K., Välimaa, T., Balčiūnienė, I., Bohnacker, U., \& Walters, J. (2012). MAIN : Multilingual Assessment Instrument for Narratives. ZAS Papers in Linguistics, 56.

Gagarina, N., Klop, D., Kunnari, S., Tantele, K., Välimaa, T., Balčiūnienė, I., Bohnacker, U., \& Walters, J. (2015). Assessment of narrative abilities in bilingual children. In S. Armon-Lotem, J. de Jong \& N. Meir (Eds.), Assessing multilingual children: Disentangling bilingualism from language impairment (pp. 243-276). Bristol: Multilingual Matters.

Gagarina, N., Klop, D., Kunnari, S., Tantele, K., Välimaa, T., Bohnacker, U. \& Walters, J. (2019). MAIN: Multilingual Assessment Instrument for Narratives - Revised. ZAS Papers in Linguistics, 63.

Gagarina, N., Klop, D., Tsimpli, I. M., \& Walters, J. (2016). Narrative abilities in bilingual children. Applied Psycholinguistics, 37(1), 11-17.

Himmelmann, N. (2005). Tagalog. In K. A. Adelaar \& N. Himmelmann (Eds.), The Austronesian Languages of Asia and Madagascar (pp. 350-376). New York: Routledge.

Kunnari, S., Välimaa, T., \& Laukkanen-Nevala, P. (2016). Macrostructure in the narratives of monolingual Finnish and bilingual Finnish-Swedish children. Applied Psycholinguistics, 37(1), 123-144.

Ledesma, H. M. L., \& Morris, R. D. (2005). Patterns of language preference among bilingual (Filipino-English) boys. International Journal of Bilingual Education and Bilingualism, 8(1), 62-80.

Lorente, B. (2013). The grip of English and Philippine language policy. In L. Wee, R. B. H. Goh, \& L. Lim (Eds.), The Politics of English: South Asia, Southeast Asia and the Asia Pacific (pp. 187-204). Amsterdam: John Benjamins.

Mahboob, A., \& Cruz, P. (2013). English and mother-tongue-based multilingual education: Language attitudes in the Philippines. Asian Journal of English Language Studies, 1, 1-19.

Manabat, A. (2016, October 16). DepEd implements mother tongue-based learning to make lessons more interactive, easier for pupils. Business Mirror. Retrieved from https://businessmirror.com.ph/2016/10/16/deped-implements-mother-tonguebased-learning-to-makelessons-more-interactive-easier-for-pupils/.

Martin, I. P. (2015). English in Mother Tongue based Multilingual Education (MTBMLE) in the Philippines. In T.W. Bigalke \& S. Sharbawi (Eds), English for ASEAN Integration: Policies and Practices in the region (pp. 110-119). Bandar Seri Begawan: Universiti Brunei Darussalam. 
Moreno, E. M., Federmeier, K. D., \& Kutas, M. (2002). Switching languages, switching Palabras (words): An electrophysiological study of code switching. Brain and Language, 80(2), 188-207.

Otwinowska, A., Mieszkowska, K., Białecka-Pikul, M., Opacki, M., \& Haman, E. (2018). Retelling a model story improves the narratives of Polish-English bilingual children. International Journal of Bilingual Education and Bilingualism, 1-25.

Pascasio, E. M. (2005). The Filipino Bilingual from a Sociolinguistic Perspective. Philippine Journal of Linguistics, 35(1), 136-145.

Paz, C. J. (1996). The nationalization of a language: Filipino. In The Fourth International Symposium on Language and Linguistics (pp. 2052-2059). Thailand.

Pearson, B. Z. (2002). Narrative Competence among Monolingual and Bilingual School Children in Miami. In D. K. Oller \& R. E. Eilers (Eds.), Language and Literacy in Bilingual Children (pp. 135-174). Bristol: Multilingual Matters.

Philippine Statistics Authority (2003), National Capital Region: Close To 10 Million Persons (Results from the 2000 Census of Population and Housing, NSO). http://www.psa.gov.ph/population-andhousing/node/428

Quebral, C. (2018). Help! My Child Can't Speak Filipino. Retrieved 15 July 2019 from http://www.familywiseasia.com/help-my-child-cant-speak-filipino/.

Raven, J. C., Court, J. H., \& Raven, J. (1976). Manual for Raven's progressive matrices and vocabulary scales.

Schachter, P., \& Otanes, F. (1972). Tagalog Reference Grammar. University of California Press.

Schneider, P., Hayward, D., \& Dubé, R. V. (2006). Storytelling from pictures using the Edmonton Narrative Norms Instrument. Journal of Speech-Language Pathology and Audiology, 30(4), 224-238.

Sicam, F. P. M., \& Lucas, R. I. G. (2016). Language attitudes of adolescent Filipino bilingual learners towards English and Filipino. Asian Englishes, 18(2), 109-128.

Smolicz, J. J. (1984). National Language Policy in the Philippines: A Comparative Study of the Education Status of 'Colonial' and Indigenous Languages with Special Reference to Minority Tongues. Southern Asian Journal of Social Science, 12(2), 51-67.

Smolicz, J. J., \& Nical, I. (1997). Exporting the European idea of a national language: Some educational implications of the use of English and indigenous languages in the Philippines. International Review of Education, 43(5-6), 507-526.

Stein, N. L., \& Glenn, C. G. (1979). An Analysis of Story Comprehension in Elementary School Children. In R. Freedle (Ed.), New Directions in Discourse Processing (pp. 53-120). Hillsdale, NJ: Ablex, Inc.

Squires, K. E., Lugo-Neris, M. J., Peña, E. D., Bedore, L. M., Bohman, T. M., \& Gillam, R. B. (2014). Story Retelling by Bilingual Children with Language Impairments and Typically-Developing Controls. International Journal of Language and Communication Disorders, 49(1), 1-14.

Thompson, R. M. (2003). Filipino English and Taglish: Language switching from multiple perspectives. Amsterdam: John Benjamins.

Trabasso, T., \& Nickels, M. (1992). The Development of Goal Plans of Action in the Narration of a Picture Story. Discourse Processes, 15(3), 249-275.

Tupas, R., \& Lorente, B. P. (2014). A 'new' politics of language in the Philippines: Bilingual education and the new challenge of the mother tongues. In P. Sercombe \& R. Tupas (Eds.), Language, Education and Nation-building (pp. 165-180). London: Palgrave Macmillan. 
Tupas, T. R. F. (2003). History, language planners, and strategies of forgetting: The problem of consciousness in the Philippines. Language Problems and Language Planning, 27(1), 1-25.

Vizconde, C. (2006). Attitudes of Student Teachers towards the use of English as Language of Instruction for Science and Mathematics in the Philippines. The Linguistics Journal, 1(3), 77-33.

Wei, L. (2000). The Bilingualism Reader. New York: Routledge.

Westby, C. (2014). Assessing and Remediating Text Comprehension Problems. In H. W. Catts \& A. G. Kamhi (Eds.), Language and reading disabilities-Pearson New International Edition (pp. 189-247). Essex: Pearson Education Limited. 